\title{
Letter from . . . Australia
}

\section{A David and Goliath story: tobacco advertising and self-regulation in Australia}

\author{
SIMON CHAPMAN
}

\section{Summary and conclusions}

A small group of health workers succeeded in getting the largest tobacco advertising campaign in Australia banned by testing a clause in the advertising industry's voluntary code of self-regulation. The group complained about a series of cigarette advertisements that featured an Australian entertainer who was popular with the young. Though the tobacco company denied the entertainer's major appeal to the young, the chairman of the Advertising Standards Council ruled that the campaign did breach the code. The delay before the complaint was adjudicated-18 months-contrasted with the speed with which a series of antismoking advertisements had been withdrawn after complaints by a tobacco company's advertisers.

MOP UP's victory in this case contains several lessons for people interested in restricting the promotional activities of multinational tobacco companies.

\section{Introduction}

In May 1980 Sir Richard Kirby, chairman of Australia's Advertising Standards Council and a retired judge from the industrial Conciliation and Arbitration Commission, ruled that a cigarette advertising campaign for Winfield cigarettes, featuring the popular Australian entertainer Paul Hogan, was in breach of the council's voluntary advertising code for cigarettes $^{1}$ (see Appendix) and should be withdrawn from all forms of publication and display. The ruling sent shock waves through the tobacco and advertising industries in Australia, since it represented not only a substantial direct loss to the tobacco company itself but also a major blow to the selfregulatory system which had been established and administered by the tobacco, advertising, and media industries.

The action that led to the ruling was initiated by a small group of health workers without backing from their Government employers. It represented a victory of David over Goliath and contains several lessons for those seeking to restrict the promotional activities of multinational tobacco companies.

\section{Advertising of Winfield cigarettes}

Winfield was introduced on to the Australian market in 1973 by Rothmans of Pall Mall (Australia) Ltd. Soon after its launch the

Movement Opposed to the Promotion of Unhealthy Products (MOP UP), Kensington, New South Wales 2033, Australia

SIMON CHAPMAN, BA, president and research officer in sociology and health education, department of preventive and social medicine, University of Sydney brand enjoyed an $11 \%$ share of the (then) \$A $745 \mathrm{~m}$ Australian retail market. By August 1978 its share had reached $20 \%$ of a SA $1166 \mathrm{~m}$ market, ${ }^{2}$ giving it a clear lead over Benson and Hedges $(16.5 \%)$, Marlboro (9.6\%), and Peter Stuyvesant (5.5\%).

The centrepiece in Winfield's advertising was an Australian entertainer, Paul Hogan. An estimated SA 28m was spent on the Hogan-based campaign in its eight-year history. ${ }^{3}$ Hogan came into the public eye through cameo appearances on a national current affairs TV programme, where he performed irreverent sketches around the day's events-a tradition in Australian humour. He subsequently became one of Australia's most highly paid entertainers. His background, as a worker on Sydney's Harbour Bridge, is known by almost all Australians and so his rise to national stardom fulfilled crucial elements of the "rags to riches" mythology with its central ideology of triumphant individualism."

Winfield's marketing success appeared to be inseparable from its Hogan-based advertising. Rothmans's faith in Hogan being able to lift Winfield's brand share even higher is perhaps shown by the fact that its advertising agency worked for 12 months on a SA $3.5 \mathrm{~m}$ Hogan-based relaunch, which was abandoned when the ruling was announced. ${ }^{3}$

\section{The protagonists: MOP UP}

In June 1979 four people with backgrounds in health education formed a public interest group called the Movement Opposed to the Promotion of Unhealthy Products (MOP UP). The group was formed to try to co-ordinate and consolidate the many isolated efforts of institutions and individuals concerned about the part that advertising and corporate promotional activities play in the epidemiology of disease. Cigarette advertising had been banned under national law from the broadcasting media in 1976, and widespread feeling existed that a complete ban could be brought about with more community support. MOP UP attracted few members, despite widespread sympathetic press coverage, especially from the Government-owned Australian Broadcasting Commission. At the time of its victory in the Winfield case MOP UP had only 115 financial supporters, with about \$A 800 in hand, and its active members were each in relatively powerless positions in their ordinary jobs. The popular, unconstituted, and unaffiliated image of MOP UP probably caused many established health and medical groups to keep away lest they became associated with a radical fringe group.

In retrospect the failure to attract the medical establishment may have been a blessing, for it allowed MOP UP to take part in some activities that would undoubtedly have been opposed by groups mindful of their "professionalism." Members held demonstrations outside cinemas that showed cigarette advertisements at children's matinees; we formed an ambiguous association with a militant billboard graffiti group (Billboard Utilising Graffitists Against Unhealthy Promotions-BUGA UP); and we placed a strongly worded advertisement in a national newspaper.

\section{Voluntary code of self-regulation for cigarette advertising}

In December 1977 the Australian Trade Practices Commission authorised the voluntary advertising code for cigarettes of the Media 
Council of Australia.* The code, modelled on a British example, has been vigorously promoted by the tobacco and media industries as an efficient alternative to government regulation; to proceedings against tobacco advertisers via the legal system; and, of course, to bans. The Federal Liberal (conservative) Government's recent rejection of the recommendations of its Senate Select Committee on Social Welfare on the prohibition of tobacco advertising ${ }^{5}$ was couched in terms that both acknowledged the importance of continuing commercial benefits to the tobacco industry and affirmed the Government's policy of supporting self-regulation. ${ }^{6}$ The cigarette advertising code was therefore implicitly linked at the highest governmental levels with the maintainance of current levels of tobacco sales. The phrasing of this rejection can be interpreted only as an acknowledgment that bans or more restrictive measures are likely to be followed by reductions in tobacco sales.

Self-regulation is a principle founded on the liberal ideology of non-intervention by governments in free enterprise systems. It is invariably cast in a rhetoric of assurances that an industry is socially responsible and dedicated to safeguarding public interest. In the case of the cigarette code the main areas of public interest said to be upheld are the values that children and non-smokers ought not to be encouraged to take up smoking and that smokers ought not to be encouraged to smoke more. Behind these values lies an acknowledgment that smoking is undesirable. Obviously there is a conflict of interests between the commercial ambitions of the tobacco industry

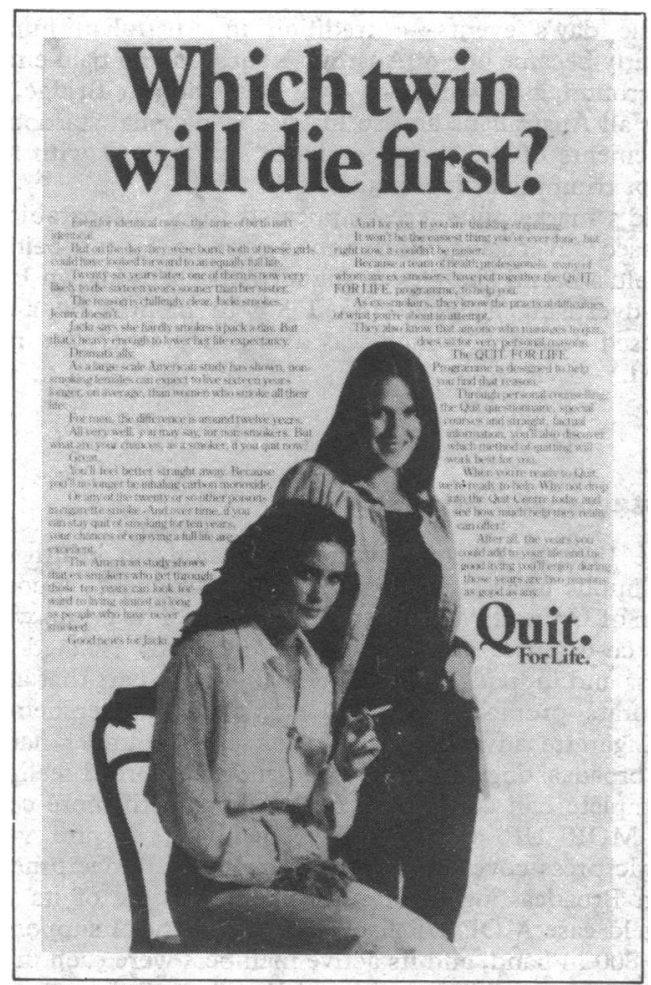

FIG 1 - This advertisement was reaccepted for publication after its headline was changed to "Which twin is more likely to die first ?" after a complaint was upheld that the original wording drew the association between smoking and illness too strongly.

in wanting to increase sales and its desire to appear to be acting in the public interest by controlling promotion, which by definition seeks to maximise sales. In the end both cannot succeed, and it would strain credulity to suggest that the tobacco industry could be expected to support actively any policy that was against its interests in the long term.

The private media industries depend on advertising revenue for their very existence. In 1978, two years after the introduction of a national ban on advertising of cigarettes on broadcasting media, the media earned SA $12.5 \mathrm{~m}$ from tobacco advertising - the twelfth largest

*The Media Council of Australia is a non-government body representing the interests of the Australian media and advertising industries. product group expenditure (Bruce Tart Research Pty Ltd, Sydney). The three main tobacco companies operating in Australia (WD and HO Wills (Australia) Ltd, Rothmans of Pall Mall (Australia) Ltd, and Philip Morris Ltd) have each recently diversified into other products to a point where their combined financial contributions to the advertising revenue of the media are unparalleled.

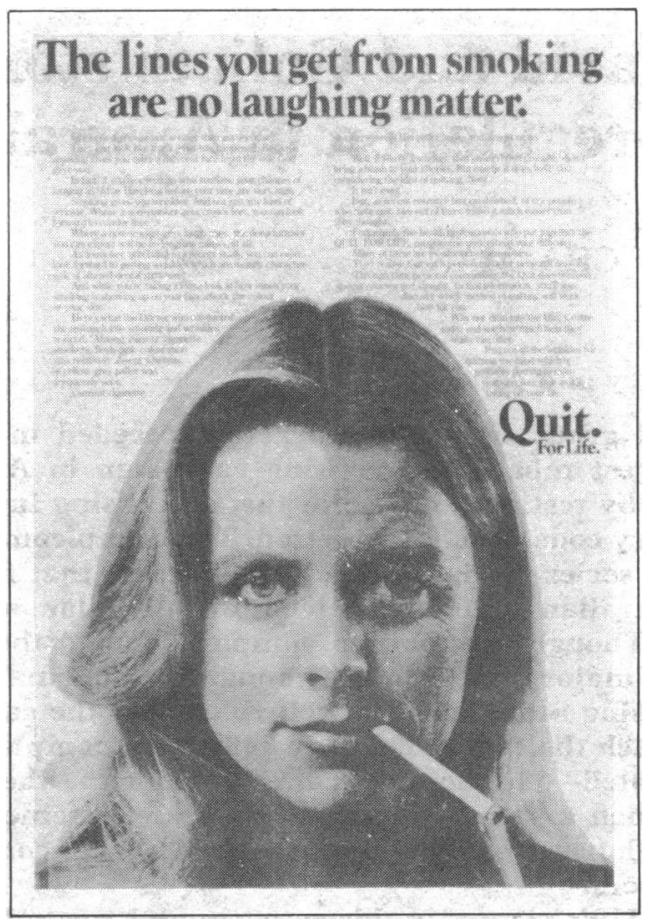

FIG 2-The headline in this advertisement was changed to: "If you get lines from smoking it's no laughing matter."

\section{Complaints against antismoking posters}

The Media Council of Australia, through its Advertising Standards Council, is responsible for administering the voluntary code. Complaints may be submitted by anyone on the grounds of offensiveness, misleading or deceptive claims, or as contraventions of the code The history of MOP UP's complaint about the Winfield-Hogan campaign, described below, can be compared with that of a complaint made in mid-1979 by the advertising company, Leo Burnett Pty Ltd, on behalf of its client Philip Morris Ltd over a series of antismoking advertisements. The advertisements (see figures 1 and 2 for examples) were alleged to offend principles of truth and deception and were withdrawn within days of the complaint being made, to be reinstated some 15 weeks later with minor alterations. The Media Council also argued that the advertisements had been placed without following protocol and being first vetted by the Advertising Standards Council.

At face value the argument was a curious one, for while the Advertising Standards Council has a vetting system for cigarette advertisements, it is not clear whether this is intended to cover antismoking advertisements. Certainly there is no direct reference in the council's publicity to their inclusion. On receipt of the tobacco company's complaint the antismoking advertisements were immediately withdrawn pending adjudication of defensive submissions by the antismoking advertisers, the Health Commission of New South Wales. On receipt of the Winfield complaint the Hogan campaign was not withdrawn and indeed, after the eventual decision 18 months later, was given three months' grace before being finally dismantled.

The case history of the Winfield complaint ought to be read in light of the publicity the Advertising Standards Council gives to its complaint-handling role:

"One of the great benefits of the self-regulation system lies in the simplicity of registering a complaint and the speed in processing of complaints. If a member of the public or any community group or advertiser believes that any advertising is misleading or offensive, they should promptly report ... [address given]."7 


\section{The Winfield complaint}

Clause 4 of the voluntary code states: "No advertising for cigarettes may include persons who have major appeal for children or adolescents under 18 years of age." On 2 November 1978 Mr John Carmichael, a founding member of MOP UP, wrote as an individual to the Advertising Standards Council: "I would like to bring to your attention each of the following cigarette campaigns which ... are obviously in breach of the code." He cited eight different campaigns, including the Hogan-Winfield campaign and claimed that the latter was in breach of clause 4.

The secretary of the council acknowledged receipt of his letter on 6 November, writing that the letter had been passed on to Sir Richard Kirby, chairman of the council, "for attention and comment." By 18 October 1979, 11 months after his first letter and following two inquiries about its progress, Carmichael had received no reply and wrote inquiring what had happened.

The council replied on 29 October 1979, saying that Carmichael's letter had "been conside red by its members in their normal working operations. The working party is an extremely busy body and, whilst it appreciates suggestions and even complaints ... has found from experience that its work is delayed rather than assisted by entering into discourses .... [it is] not considered that you are entitled to a reply. evaluating your various complaints." (My italics.) The letter pointed out that Carmichael had complained about "campaigns" and not individual advertisements, and so could not be ruled on because of the council's function in considering only specific advertisements.

Carmichael replied on 7 November 1979 with formal complaints about specific advertisements, writing: "How do you justify taking just short of a year to inform me that I have not met your criteria for lodging a formal complaint ?" The council replied on 22 November 1979, over a year since Carmichael's first letter, that his complaints would be considered on 17 December 1979 by the council and pointed out that Carmichael had first used the word "complaint" in the letter of 7 November 1979. This piece of pedantry was curious since the council itself had referred specifically to his "complaints" in the letter of 29 October 1979, before he had actually used the word. His intentions were obvious.

In the mean time the Regional Drug and Alcohol Information and Resource Centre, St Marys, New South Wales, had thrown an extra hat into the ring. On 4 October 1979 its co-ordinator, Mr David Small, had sought clarification from the Media Council of Australia about the precise meaning of "major appeal" in clause 4 of the code. Small cited private audience research data that showed that the Paul Hogan television programme topped the popularity ratings among 5- to 12-year-old Australian children, with an average 282000 viewers naming the programme as their favourite in a rating period. ${ }^{3}$ On a per caput basis marginally more children nominated the programme than did adults.

Small wrote on 31 November 1979 lodging a formal complaint about Winfield. The Australian Publishers' Bureau, another affiliated body of the Media Council, replied that the matter was being referred to the Joint Working Party (Cigarettes) chaired by a senior medical officer of the NSW Government's Health Commission.

This referral did not take place until 4 December, and in a letter dated two weeks later the government medical representative made the following points on behalf of the working party:

“(1) That Hogan thus - represents a special problem in what might be seen as a grey area of influence (or interface) in the constant 'cold war' that goes on between advertisers and their opponents.

(2) That radio and television advertising of cigarettes is banned. Therefore when Hogan appears on television he is doing something else.

(3) That Hogan as a performing artist has the freedom to contract his services to varied clients, and it is important for the future of entertainers that such freedom be maintained despite any seeming disadvantages."

He concluded that it would be unlikely that Sir Richard Kirby, as chairman of the Advertising Standards Council and final arbiter in any decision regarding Hogan, would agree that a contravention of the code had been established. He wrote:

"Though these views may not be welcome they embody the cold, logical reasoning of experience and we agree that no useful advantage is to be obtained by taking your particular concern further. We both recognise that the words of clause 4 of the code can give rise to considerable argument and polarisation of view. That merely reflects the fact that some areas of human activity go beyond present limits of regularbility, and we know of no acceptable way in which the matter can be satisfactorily resolved." (My italics.)
These words are an admission of the inherent inoperability of clause 4 of the code. It is disturbing that they should have come from a representative of a Government health commission, for someone representing the health interests of a State might have been expected to have made such a conclusion in the context of a stand against the code. Instead the Government medical representative and other health department representatives on the working party unwittingly aligned themselves with the vested interests seeking to uphold the code as a viable regulatory mechanism.

A final hearing on the Winfield case was held on 2 May 1980. A recent joint survey by MOP UP and the Australian Consumers' Association of 475 12-15-year-olds which showed Winfield to be their clear and unchallenged cigarette of choice was submitted as further evidence along with a petition from psychologists and psychiatrists stating that their professional opinion was that Hogan was a strong role model for young adolescents and a declaration by a lecturer in psycholinguistics that the complainants' interpretation of the words "major appeal" was sound. Rothmans, Winfield's owners, based their defence of Hogan on the argument that the corollary of "major appeal to children" was "minor appeal to adults." Since Hogan was also popular with adults, Rothmans claimed that clause 4 of the code was not applicable in the case of Hogan. The time that elapsed from Carmichael's first complaint to the final hearing and ruling against the use of Hogan in Winfield was 18 months to the day.

\section{Aftermath and conclusions}

Rothmans were clearly confident that the complaint would not be upheld, as shown by their substantial investment in a proposed relaunch featuring Hogan. Rothmans had the option of ignoring the Kirby ruling, as it was not enforceable by law. Indeed this was apparently discussed by its management, ${ }^{3}$ but a decision was taken to abide by the ruling.

The Advertising Federation of Australia responded to the ruling by suggesting that all regulatory codes should be subject to an urgent and critical review to test their compatibility with the advertising industry creed "If it's legal to sell, it should be legal to advertise." 8 This suggestion indicates that the industry cannot tolerate a self-regulation system that actually regulates advertising, but still sees that some form of "complaint-proof" code is needed.

This story reveals crucial aspects of the voluntary code and the Media Council's role in its operation as the appearance of self-regulation in the absence of actual self-regulation. ${ }^{9}$ The code is the embodiment of a carefully and, until the Hogan case, successfully stage-managed public relations effort by the industries concerned to divert any attempt at Government regulation or banning. While Rothmans's agreement to comply with the ruling against Hogan may seem a remarkable sacrifice for private enterprise to have made, it is merely a gesture in comparison to the far wider issue of self-regulation being preserved.

At the time when the tobacco and media industries drafted the voluntary code in 1977 there was virtually no organised public opposition to cigarette advertising in Australia. The industries clearly did not envisage a group like MOP UP emerging, and their lack of vigilance in anticipating concerted attempts at challenging the code's clauses is perhaps the overriding factor responsible for their loss.

There are several other factors which, in retrospect, can be seen to have been vital to the case reaching the conclusion that it did. The willingness of certain sections of the Australian press and media to cover the progress of the case was central among these. The complainant Carmichael could easily have been dismissed by the Advertising Standards Council as a socially invisible "nut-case," whose complaints on plain paper could be fobbed off in the council's own good time. The formation of MOP UP around Carmichael's complaint transformed the situation from one of "irate (somewhat extreme) citizen" versus "virtually unknown industrial regulatory body" to the much more newsworthy conflict of "concerned group of citizens" versus "the nasty tobacco industry, trying to influence our children." 
Tactically MOP UP withheld the story of their complaints until enough examples of conflict, such as overly delayed responses from the council, were available to create a good "story" for the media. The angles of tobacco companies trying to influence children and of ordinary concerned citizens trying to get satisfaction from big business and the continual passage of time between the first complaint and the opportunity to have a judgment by an independent judge were emphasised. MOP UP was able to get news coverage from both the in-depth programmes, concerned at the wider implications of the action, and from the "heart-strings" press via the mythological themes of, "Can the little man win ?" and, "Against all odds, can they do something about our children being seduced into smoking?" Journalists' questioning consistently revealed these themes as holding the news value of the whole procedure.

The question of whether the industry was capable of selfregulation was not newsworthy and seldom survived editing. But it was undoubtedly the joker in the pack. The self-regulation system, designed by the industry as a fend against the threat of Government regulation, must also be seen as a weapon that could be used by tobacco companies against one another in the competitive struggle for market share. Had they elected to ignore the Kirby ruling, Rothmans would have drawn strong protest from their competitors as undermining the industry's "gentleman's agreement" to abide by the code.

The action described in this paper was undertaken by people working in health education who were each critical of the dominant individual-oriented approach in Australian and Western health education. ${ }^{10}$ By directing preventive efforts "upwards" in an attempt to control advertising we avoided the victim-blaming implied in preventive efforts directed at individuals. By forming a public-interest group around a public health issue we turned the complaint from a private issue between an individual and a regulatory body into a conflict of competing private and public interests.

\section{Appendix \\ VOLUNTARY ADVERTISING CODE FOR CIGARETTES IN AUSTRALIA}

(1) Cigarette advertising shall be directed only to adult smokers and intended to effect a change of brand.

(2) Except in crowd or other scenes, where the background is not under the control of the advertiser, no characters shall be employed in cigarette advertisements who are under 25 years of age.

(3) No family scenes of father and/or mother handling cigarettes in front of children may be included.

(4) No advertising for cigarettes may include persons who have major appeal for children or adolescents under 18 years of age.

(5) Where a cigarette packet is included in advertising it will bear the health warning.

(6) Advertisements shall not include well-known past or present athletes or sportsmen smoking cigarettes nor anyone smoking cigarettes who is participating or has just participated in physical activity requiring stamina or athletic conditioning beyond that of normal recreation.

(7) When an advertisement depicts success or distinction it shal not be implied that this is due to cigarette smoking. Advertising may use attractive models or illustrations thereof, provided there is no suggestion that the attractiveness is due to cigarette smoking.

(8) Cigarette advertising must be aimed only at smokers, but must not be intended to imply or convey that all persons are smokers. In practice, where there is a group of at least four people featured in an advertisement, at least one shall be shown as a non-smoker.

(9) Cigarette advertising must not show exaggerated satisfaction from the act of smoking.

(10) No advertisement may claim health properties from any cigarette.

\section{References}

1 Media Council of Australia. Voluntary advertising code for cigarettes in Australia. Australian Advertising Industry Council, 1979.

2 William Tilley, Hudson, Evans and Co. The luxury or necessity of tobacco. The implications for Amatil, Philip Morris and Rothmans. Sydney: William Tilley, Hudson, Evans and Co (Stockbrokers), 1978.

3 Anonymous. Winfield campaign changes course. Advertising News 1980 May 23:2.

4 Chapman SF, Egger G. Myth in cigarette advertising and health promotion. Int $\mathfrak{f}$ Health Educ (in press).

5 Senate Standing Committee on Social Welfare. Drug problems in Australia -an intoxicated society? Canberra: AGPS, 1977:3-11.

6 Anonymous. Sydney Morning Herald 1980 March 20.

7 Australian Advertising Industry Council. Self-regulation in Australian advertising. Sydney: AAIC, 1979:11.

8 The Australian 1980 May 12.

9 Persky J. Self-regulation of broadcasting-does it exist? Fournal of Communication 1977; Spring:202-10.

10 Brown ER, Margo GE. Health education: can the reformers be reformed ? Int $\mathcal{F}$ Health Serv $1978 ; 8(1): 3-26$.

(Accepted 9 September 1980)

\section{CHANCE, COINCIDENCE, SERENDIPITY}

\section{The biter bit}

One Tuesday afternoon in the winter of 1945 two young students, both aspiring cardiac physicians, sat on the extreme right in the front of cardiac department outpatients at the London Hospital. Dr Williams Evans was teaching; consequently the classroom was packed to overflowing. One of the two, Tommy Gibson, now of Vermont, was chosen for inquisition. The other felt that by giving the perfect answer to every question Tommy might not be ensuring the advancement of his career in cardiology, for humility was then a prerequisite and he was giving the impression, quite wrongly, that he thought his knowledge was complete.

Suddenly the chief rose and advanced three paces. That glint in eye, mouth characteristically set, meant that poor Tommy was about to be disabused or disembowelled. The ensuing dialogue went something like this-though I wish I'd recorded it then.

WE: (it was to be a historical digression along paths unfamiliar for unformed minds) Who invented the polygraph, Gibson?

TG: Sir James Mackenzie, sir, in 1902.

WE: Where was he born, Gibson?
TG: In Scone, Perthshire, sir.

WE: You know he came to the London Hospital.

TG: Of course.

WE: And before that, Gibson?

TG: He was in general practice, sir.

WE: (intending the coup de grâce) Ah, but where, Gibson?

TG: (serenely) In Burnley, sir.

WE: What street in Burnley, Gibson?

TG: It is called Bank Parade, sir.

WE: (showing trifling signs of discomfiture) What number Gibson?

TG: (class on tenterhooks) No 68 Bank Parade, sir.

WE: There is a plaque by the front door isn't there, Gibson? What does it say?

TG: Actually it's above the door, sir, slightly to the right. Under the Burnley coat of arms it says "Sir James MacKenzie, MD, LLD, FRS, FRCP (1853-1925) who achieved fame by his researches in connection with diseases of the heart, was from 1879 to 1907 a general practitioner in Burnley and lived in this house."

WE: (generous, even in defeat) My dear boy, do tell me how on earth do you know so much about MacKenzie?

TG: My father, John Gibson, took over his practice, sir. I was born in Sir James's old consulting room.

Serendipitous?-EIRIAN WILLIAMS. 